Supplement of The Cryosphere, 13, 2241-2257, 2019

https://doi.org/10.5194/tc-13-2241-2019-supplement

(C) Author(s) 2019. This work is distributed under

the Creative Commons Attribution 4.0 License.

(c) (1)

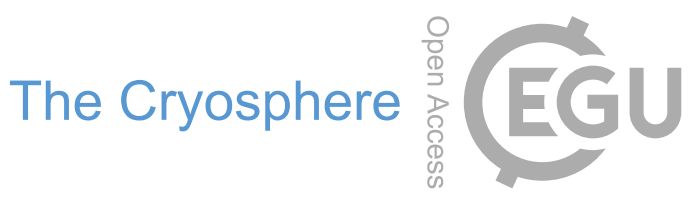

Supplement of

\title{
Greenland Ice Sheet late-season melt: investigating multiscale drivers of K-transect events
}

Thomas J. Ballinger et al.

Correspondence to: Thomas J. Ballinger (tballinger@txstate.edu)

The copyright of individual parts of the supplement might differ from the CC BY 4.0 License. 


\begin{tabular}{|c|c|c|c|c|}
\hline Year & DOA [d=0] & DOA Anomaly (d) & DOA [-60,-31] & DOA [-30,-1] \\
\hline 2011 & 30 Oct (303) & -10.65 & 31 Aug - 29 Sep & 30 Sep - 29 Oct \\
\hline 2012 & 17 Nov (322) & 8.01 & 18 Sep - 17 Oct & 18 Oct -16 Nov \\
\hline 2013 & 13 Nov (317) & 3.10 & 14 Sep -13 Oct & 14 Oct -12 Nov \\
\hline 2014 & 21 Nov (325) & 11.65 & 22 Sep -21 Oct & 22 Oct -20 Nov \\
\hline 2015 & 12 Nov (316) & 2.25 & 13 Sep -12 Oct & 13 Oct -11 Nov \\
\hline
\end{tabular}

27

28 Table S1. Baffin Bay sea ice dates of advance (DOA) for each year in the study period (2011-2015) with the day of

29 year (DOY) in parentheses (column 2), the date anomaly with respect to the 1981 - 2010 mean (column 3), and

30 annual date windows preceding each respective DOA (column 4 and 5).

31

32

33 


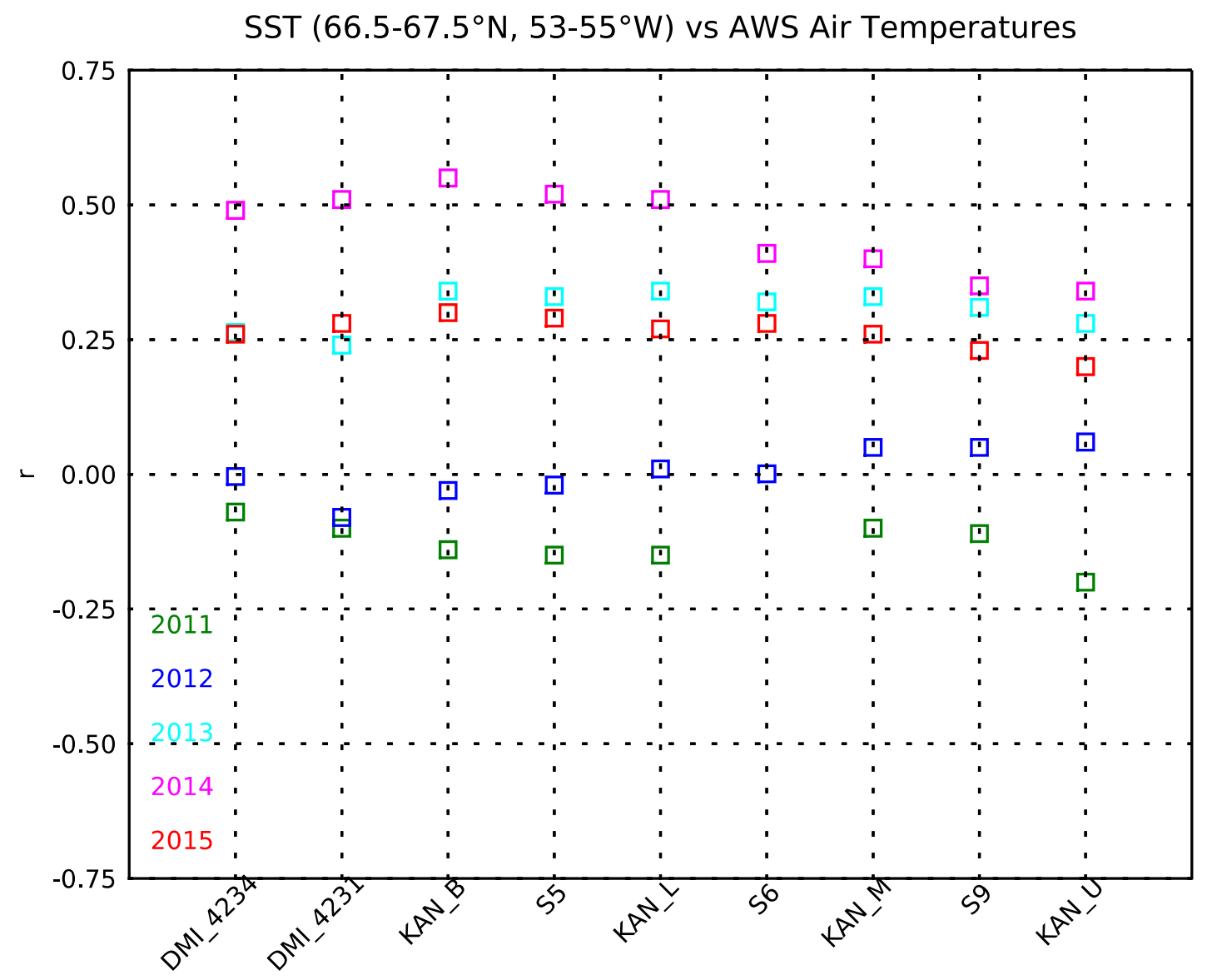

Figure S1. Detrended Pearson (r) correlation coefficients signaling intraseasonal fluctuations between Danish Meteorological Institute (DMI) near-coastal or K-Transect automatic weather station (AWS) air temperatures and sea surface temperatures (SST) surrounding Sisimiut (i.e. WMO code 4234). The SST domain matches the local date of sea ice advance (DOA) domain outlined in Fig 3a-f. The SST product is described in Ballinger et al. (2018b) and DMI air temperatures are from Cappelen $(2018,2019)$. The coefficients are calculated over the 60 -day (i.e. $[-60,-1])$ period preceding the DOA from 2011 to 2015 and $\mathrm{p} \leq 0.05$ for $\mathrm{r} \geq|0.26|$. The $\mathrm{S} 6$ coefficient for 2011 is missing due to an inadequate number of air temperature values. DMI_4234 correlation coefficients overlap ( $\mathrm{r}=0.26)$ for 2013 and 2015. 